Relato de Experiência

Mariana Pereira da Silva (iD) https://orcid.org/0000-0002-8666-3555

Marcia Hespanhol Bernardo ${ }^{a}$

(iD) https://orcid.org/0000-0002-8068-6238

\section{Grupo de reflexão em saúde mental relacionada ao trabalho: uma contribuição da psicologia social do trabalho}

\author{
Discussion group on work-related mental health: \\ a Social Psychology of Work contribution
}

a Pontifícia Universidade Católica de Campinas, Pós-Graduação em Psicologia. Campinas, SP, Brasil.

Contato:

Mariana Pereira da Silva

E-mail:

mariananox@gmail.com

Trabalho baseado em dissertação de mestrado intitulada $O$ sonho que se tornou pesadelo: a vivência de um grupo de trabalhadores da indústria automobilística, de Mariana Pereira da Silva, defendida em 2018 na Pontifícia Universidade Católica de Campinas (PUC-Campinas), Campinas, SP, Brasil.

Os autores declaram que o trabalho não foi subsidiado e que não há conflitos de interesses.

Os autores informam que o trabalho não foi apresentado em eventos científicos.

Recebido: 06/02/2018

Revisado: 20/06/2018

Aprovado: 25/06/2018

\section{Resumo}

Objetivo: apresentar e discutir uma proposta de intervenção grupal com trabalhadores de uma indústria automobilística que apresentavam intenso sofrimento psíquico. Métodos: intervenção com métodos participativos, abrangendo 14 trabalhadores de uma mesma empresa, com queixas de adoecimento físico e mental relacionado ao trabalho. Os participantes compartilharam suas vivências cotidianas relacionadas ao trabalho em um grupo de reflexão, aberto e construído coletivamente, realizado no Centro de Referência em Saúde do Trabalhador (Cerest) de Campinas (SP), ao longo de 11 encontros, durante seis meses. Para estimular a discussão acerca das experiências cotidianas relacionadas ao trabalho e seus impactos sobre a vida e a saúde dos trabalhadores, utilizaram-se estratégias metodológicas como rodas de conversa, dinâmicas e materialidades mediadoras, como filmes, textos e imagens. Resultados: as intervenções no grupo de reflexão geraram discussões sobre temas como trabalho no capitalismo, culpabilização dos trabalhadores pelo adoecimento, suas histórias e seus novos projetos de vida, e a importância da união e da solidariedade entre eles. Conclusão: o grupo auxiliou no desenvolvimento de reflexões críticas pelos trabalhadores, fazendo-os se sentir menos culpados, mais fortalecidos, unidos, solidários entre si e mais ativos na busca por transformação das condições e da organização do trabalho.

Palavras-chave: saúde do trabalhador; saúde mental relacionada ao trabalho; intervenção grupal; pesquisa-intervenção.

\begin{abstract}
Objective: to present and discuss a group intervention proposal involving workers from a car industry who were experiencing intense psychical suffering. Methods: participative intervention with 14 workers employed in the same company who complained about physical and mental work related illnesses. The participants shared their work-related daily experiences in an open and collectively built discussion group; 11 meetings were held for six months at the Occupational Health Reference Center (Cerest) of Campinas, SP, Brazil. Methodological strategies, such as conversation circles, dynamics and mediating materialities (films, texts and images), were adopted to stimulate the discussion on daily work-related experiences and their impacts on workers' life and health. Results: the interventions in the discussion groups instigated discussions on topics such as work under capitalism, workers' culpability regarding their illnesses, their stories and new life projects, and the importance of their union and solidarity. Conclusion: the group helped the workers to develop critical reflections, to feel less guilty, stronger, more united and solidary with each other, as well as more active in their search for changing work conditions and organization.
\end{abstract}

Keywords: occupational health; work-related mental health; group intervention; intervention-research. 


\section{Introdução}

Fazer-se presente na área da saúde do trabalhador, com foco na saúde mental relacionada ao trabalho, é algo que apresenta diversos desafios e obstáculos. Pensando nas contribuições da psicologia, vemos que, historicamente, este saber se construiu essencialmente vinculado aos interesses da gestão, e não aos dos trabalhadores e à sua saúde ${ }^{1}$. Os desafios e obstáculos, nesse sentido, estão presentes ao atuarmos de forma contra-hegemônica, com um viés crítico, que percebe e busca compreender as contradições existentes no mundo do trabalho, de forma comprometida com a transformação social.

Essa outra forma de atuação da psicologia é possível a partir da perspectiva chamada psicologia social do trabalho ${ }^{2}$ que, de acordo com Bernardo, Sousa, Pinzón e Souza ${ }^{3}$, surgiu a partir de pesquisas em psicologia social e da aproximação de profissionais da psicologia com movimentos sociais dos trabalhadores que lutavam pela saúde do trabalhador e por um olhar mais crítico sobre as relações de trabalho. As autoras também afirmam que, nessa perspectiva, as relações no mundo do trabalho são entendidas como assimétricas, permeadas por aspectos históricos, sociais e subjetivos, que devem ser analisados para a compreensão do trabalho enquanto fenômeno complexo ${ }^{3}$.

No contexto contemporâneo, o trabalho encontra-se cada vez mais precarizado e flexível ${ }^{4}$ e, assim, os trabalhadores passam a vivenciá-lo de forma mais instável, insegura e transitória. Para atender às exigências do mercado e das tecnologias, ocorrem mudanças constantes e, aos trabalhadores, cabe acompanhá-las e se adequar a elas, sendo tão mais competitivos, individualistas, multifuncionais e versáteis quanto for possível. Nesse sentido, o $1^{o}$ Boletim Quadrimestral sobre Benefícios por Incapacidade de $2017^{5}$, da Previdência Social, discute a necessidade de nos atentarmos aos impactos desse contexto, já que a tendência de crescimento do adoecimento mental relacionado ao trabalho é observada em todo o mundo. O documento traz dados significativos sobre a concessão de benefícios por incapacidade para o trabalho, temporária ou definitiva, motivada por adoecimento mental e mostra que os transtornos mentais e comportamentais ocupam a terceira posição entre os motivos para afastamento do trabalho, totalizando 668.927 casos no período entre 2012 e 2016. Além disso, o boletim ressalta que a Organização Internacional do Trabalho (OIT) relaciona o adoecimento mental à organização, às condições e às relações estabelecidas dentro do trabalho. Assim, vemos a importância de os serviços de saúde, os empregadores, os trabalhadores, os sindicatos, as organizações e as instituições refletirem sobre essa temática.

Diante dessa realidade, com base em Bernardo e Pereira ${ }^{6}$, um dos compromissos do psicólogo, quando inserido no âmbito do trabalho, é se atentar para os micro e macrocontextos sociais para atuar de forma crítica e engajada com a transformação social, visando a uma sociedade mais justa e igualitária. Quando nos deparamos com relações produtivas desiguais, que resultam na exploração e na alienação dos trabalhadores, cabe também aos profissionais a elucidação e a denúncia desse processo, e não a atuação de forma conivente com as desigualdades sociais produzidas dentro do trabalho. Defende-se, aqui, portanto, que o psicólogo não favoreça a manutenção da manipulação e dos interesses de classe, mas que atue com práticas direcionadas a transformações das condições de exploração dos trabalhadores.

É a partir dessa perspectiva que se deu o processo de intervenção-pesquisa que será discutida neste artigo. Esteves, Bernardo e Sato ${ }^{7}$ utilizam Paulo Freire e Martín-Baró em suas discussões sobre as fontes do pensamento e das práticas em psicologia social do trabalho. Os autores discorrem sobre intervenção dentro dessa perspectiva, e as ideias trazidas por eles estão de acordo com o que se propôs durante as intervenções. Segundo os autores ${ }^{7}$, "pesquisa e intervenção são atividades articuladas e que se alimentam mutuamente" (p. 66). É como se, nesse sentido, fazer pesquisa demandasse uma intervenção, e vice-versa.

É interessante destacar que Paulo Freire ${ }^{8}$ e Martín-Baró ${ }^{9}$ são autores que trazem grandes contribuições para percebermos o compromisso das pessoas com sua realidade social enquanto responsáveis por sua transformação. Considerando as características da realidade latino-americana, esses autores defendem uma sociedade mais libertadora e menos opressora, com mais justiça social e igualdade. Essa concepção permeou todo o processo de intervenção a ser discutido aqui.

Tendo isso em vista, durante o processo de mestrado do qual esse artigo é fruto, teve-se acesso a uma demanda ${ }^{b}$ do Centro de Referência em Saúde do Trabalhador (Cerest) de Campinas. Essa demanda sinalizava que o número de casos de adoecimento mental e físico - especialmente as lesões por esforços repetitivos (LER) ${ }^{\mathrm{b}}$ - vinha

b De acordo com Lima ${ }^{10}$, as LER consistem em lesões desencadeadas por movimentos repetitivos e rápidos realizados pelos trabalhadores, sob pressão para aumentar a produção, que impactam no ritmo de trabalho e também na saúde mental do portador. 
aumentando dentro de uma indústria automobilística da região. O serviço realizou algumas ações, como encontros com trabalhadores adoecidos dessa empresa, voltados à escuta da demanda, para nortear a visita ao local para fins de fiscalização na vigilância em saúde. Nos encontros com os trabalhadores, estes relatavam que vivenciavam intenso desgaste no cotidiano de trabalho e disseram que as ações da empresa eram totalmente contrárias à sua saúde. Demonstraram que se sentiam muito culpados por terem adoecido, como se fossem fracos ou incapazes.

Além disso, quando os técnicos do Cerest foram à empresa, junto com o Ministério Público do Trabalho (MPT), perceberam que os trabalhadores estavam imersos em um contexto de violência psicológica dentro do trabalho que repercutia em processos de adoecimento físico e mental. As informações obtidas geraram uma ação dentro do MPT, ainda em andamento, com vistas à prevenção de problemas de saúde relacionados ao trabalho.

Independentemente de tais ações, era nítido o quanto os trabalhadores que já apresentavam sintomas de sofrimento/adoecimento psíquico ainda precisavam de um espaço para compartilhar e elaborar o que sentiam em relação ao trabalho. Porém o serviço não dispunha de um psicólogo em seu quadro de funcionários, pois, conforme afirmam Keppler e Yamamoto ${ }^{11}$, esse profissional não tem presença obrigatória na equipe mínima dos Cerest, embora isso não queira dizer que sua presença não seja necessária.

Ter ciência dessa demanda e da ausência de um psicólogo no serviço, portanto, fez com que se pensasse sobre a possibilidade de se realizar uma pesquisa que envolvesse o atendimento a esses trabalhadores, focalizando os processos de saúde-adoecimento mental relacionados ao trabalho. Nesse sentido, o presente artigo tem como objetivo apresentar e discutir uma proposta de intervenção grupal com trabalhadores de uma indústria automobilística que apresentavam intenso sofrimento psíquico.

\section{Percurso metodológico}

Entende-se que acessar o cotidiano de trabalho por meio dos próprios trabalhadores é algo que permite que estejamos mais próximos de suas experiências, já que são eles que vivenciam, diariamente, o trabalho em seus múltiplos processos. Considerar os trabalhadores como protagonistas de sua prática cotidiana foi proposto por Oddone et al. ${ }^{12}$, a partir da perspectiva conhecida como
Movimento Operário Italiano. Segundo os autores, são os trabalhadores que vivenciam os problemas de saúde no trabalho e, por isso, a avaliação das condições de trabalho e de saúde deve partir da subjetividade deles próprios. Essa perspectiva influenciou de forma marcante diversos trabalhos de pesquisa e intervenção nas últimas décadas, tais como a medicina social latino-americana ${ }^{13}$, a clínica da atividade ${ }^{14}$, a psicodinâmica do trabalho ${ }^{15}$, a ergonomia da atividade ${ }^{16}$ e, no Brasil, todo o campo da saúde do trabalhador ${ }^{17}$. Todos consideram que o protagonismo dos trabalhadores permite o acesso a problemáticas unicamente resgatáveis a partir de seu ponto de vista.

A intervenção aqui apresentada partiu desse princípio, até mesmo para guiar a forma como o processo se construía. A proposta de intervenção foi grupal, baseada no estudo de Sato et al. ${ }^{18}$, que se utilizaram de uma forma semelhante há mais de vinte anos com trabalhadores portadores de LER - doença relacionada ao trabalho cuja magnitude crescia na época e passava a ser considerada um problema de saúde pública. Hoje, embora esse problema continue, são os transtornos mentais relacionados ao trabalho que se destacam. Como afirmam as autoras, o grupo pode propiciar uma vivência de resgate de valores, contra o individualismo e a favor da cooperação, apontando saídas coletivas e servindo de espaço para que a culpa possa ser ressignificada: "O grupo facilita a construção de estratégias individuais e coletivas no sentido de melhorar a qualidade de vida, requerendo tais estratégias a adoção de uma postura ativa diante da situação"18.

Assim, foi proposta inicialmente uma atividade grupal denominada "Grupo de reflexão sobre trabalho e saúde", tendo como participantes os trabalhadores vinculados à indústria automobilística acima referida, sendo coordenado por uma das autoras deste artigo e acompanhado por duas profissionais do Cerest. Desde o início foi acordado que o grupo teria um caráter aberto, ou seja, não haveria controle de presença ou exigência de um número máximo de faltas. No total, ocorreram onze encontros realizados ao longo de seis meses.

Após cada encontro, as experiências e impressões eram registradas em diários de campo, os quais serviram como objeto de análise. Segundo Weber ${ }^{19}$, esses instrumentos são comumente utilizados na etnografia para registro das informações obtidas, e neles estão contidos os eventos observados, as impressões pessoais do pesquisador sem restrições, os discursos e as posições dos participantes da pesquisa, as relações estabelecidas em campo, entre outros aspectos que evidenciam o contato entre os envolvidos na pesquisa e podem enriquecer o processo de análise. Os diários foram escritos 
imediatamente após os encontros para que os detalhes não fossem perdidos. Neles, também foram registradas as experiências vividas pela pesquisadora relativas ao tema pesquisado, às reuniões e às conversas com os profissionais do Cerest, além de conversas informais, também com os trabalhadores participantes.

A proposta de intervenção-pesquisa foi autorizada pela Secretaria Municipal de Saúde de Campinas, bem como foi aprovada pelo o Comitê de Ética em Pesquisa da Pontifícia Universidade Católica de Campinas (CAAE 60506416.6.0000.5481). Somente após essas autorizações, pôde-se realizar o primeiro contato com os trabalhadores.

\section{Resultados e discussão}

\section{Conhecendo os participantes}

No total, participaram 14 trabalhadores, todos vinculados a uma indústria automobilística do interior de São Paulo, que procuraram o Cerest de Campinas (SP) por apresentarem queixas de adoecimento que avaliavam estarem relacionadas ao trabalho. As queixas apresentadas por eles referiam-se tanto a agravos físicos - como as LER e outras lesões - quanto a agravos à saúde mental - como sofrimento intenso, depressão e ansiedade.

A indústria automobilística à qual esses trabalhadores estavam vinculados adotava uma forma de organização do trabalho característica do toyotismo, um modelo de gestão e produção que, conforme afirma Bernardo ${ }^{20}$, estimula o individualismo, a competitividade, a terceirização e a flexibilização. Segundo a autora, as características desse modelo podem colaborar para o desenvolvimento de agravos à saúde mental relacionados ao trabalho. A empresa será aqui nomeada Tamaru ${ }^{\mathrm{C}}$, assim como no estudo de Bernardo ${ }^{20}$.

Os participantes eram todos do sexo masculino, com idades que variaram de 26 a 45 anos, com média de 36 anos. Com relação à função dentro da empresa, eles exerciam atividades de montadores, soldadores ou preparadores de pintura. O tempo de trabalho na montadora, por sua vez, variou de 4 a 18 anos, com uma média de 10 anos. O Quadro 1 caracteriza, de forma breve, os principais problemas de saúde relatados por cada trabalhador que participou da pesquisa ao longo das atividades grupais e algumas características individuais que eles mesmos destacaram. Ressalta-se que, nesse quadro, não foram inseridas informações mais detalhadas, tais como idade, função e tempo de trabalho, a fim de garantir o anonimato dos participantes. Com essa mesma finalidade, os nomes atribuídos a eles também são fictícios.

Essas breves características foram, em sua maioria, atribuídas pelos próprios trabalhadores. É interessante que, durante rodadas de apresentação, por exemplo, eles diziam seus nomes, suas idades, seus respectivos tempos de trabalho e, logo depois, relatavam suas lesões. Isso nos mostra o quanto a identidade de "lesionado" - termo frequentemente utilizado por todos - estava presente em cada um deles. Vemos também que o processo de saúde-adoecimento dos participantes possuía muitos fatores em comum, iniciando-se a partir de agravos à saúde física, principalmente com lesões osteomusculares nos ombros, na coluna, nos punhos e nos joelhos, dependendo da postura em que trabalhavam. Os trabalhadores disseram que os agravos à saúde mental se iniciavam após as lesões físicas, constatação que está de acordo com a afirmação de Salerno, Silvestre e Sabino ${ }^{21}$ de que é comum a manifestação de adoecimento mental por pacientes portadores de LER/Dort, por exemplo. Os autores afirmam que é como se houvesse um círculo vicioso perverso de dor crônica e de sofrimento mental, que causam grande impacto na vida do trabalhador como um todo. Tudo isso aponta a indissociabilidade da saúde mental e da saúde física, tal qual afirma Seligmann-Silva ${ }^{22}$. A maioria dos trabalhadores relatava depressão, estresse, sofrimento no trabalho e nos demais âmbitos da vida, como o pessoal e o familiar.

As histórias relativas ao processo de adoecimento eram retratadas de forma similar pelos participantes. Depois de sofrerem lesão, eram afastados e, logo em seguida, passavam por um processo de reabilitação e volta ao trabalho. Dois deles, inclusive, trabalhavam quando do início do grupo, mas tiveram que se afastar durante seu andamento devido a lesões físicas, embora isso não tenha inviabilizado suas participações. Houve um trabalhador que já havia se afastado onze vezes, duas delas por depressão. O tempo mais longo de afastamento foi retratado por outro participante e correspondeu a oito anos. Cabe ressaltar que esse participante foi demitido, mas entrou com um recurso judicial, sendo reintegrado ao trabalho. Os demais não relataram demissão, mas referiam o receio de serem demitidos.

c A indústria automobilística na qual os participantes trabalham não será identificada especialmente para protegê-los. Mas outro aspecto considerado diz respeito ao fato de que não é exclusividade dela a adoção da lógica do toyotismo e de um modelo de gestão que estimula o individualismo, a competitividade, a terceirização, a flexibilização e outras características que podem adoecer os trabalhadores, tanto física quanto mentalmente. 
Quadro 1 Breve descrição dos participantes da pesquisa

\begin{tabular}{|c|c|}
\hline Nome (fictício) & Agravos à saúde \\
\hline Abraão & $\begin{array}{l}\text { Lesões nos ombros, punhos, cotovelos e LER/Dort. Relatava dificuldade diária para trabalhar, devido às dores que } \\
\text { sentia, além de tristeza e desmotivação. }\end{array}$ \\
\hline Timóteo & $\begin{array}{l}\text { Lesões nos ombros, na coluna e nos joelhos. Queixava-se de que a empresa o fazia sofrer muito, tanto física quanto } \\
\text { psicologicamente. }\end{array}$ \\
\hline Daniel & $\begin{array}{l}\text { Lesões nos ombros e LER/Dort. Após seu afastamento, foi reinserido no trabalho na mesma função, o que lhe gerou } \\
\text { mais lesões. }\end{array}$ \\
\hline José & $\begin{array}{l}\text { Lesões nos ombros, na coluna e na clavícula. Diagnosticado com depressão, afirmava não ter mais saúde e nem } \\
\text { sequer perspectivas de tê-la novamente. }\end{array}$ \\
\hline Davi & Lesões nos ombros. Optou por não se submeter a intervenções cirúrgicas. \\
\hline Jonas & $\begin{array}{l}\text { Lesões nos punhos. Era um dos participantes com sofrimento psíquico muito intenso. Sentia-se perseguido, } \\
\text { humilhado e relatava ideias suicidas. }\end{array}$ \\
\hline Saulo & $\begin{array}{l}\text { Lesões nos joelhos. Após afastamento, foi reinserido no trabalho na mesma função, o que the gerou mais lesões. } \\
\text { Sentia-se triste, desmotivado e com medo. }\end{array}$ \\
\hline Moisés & $\begin{array}{l}\text { Lesões nos ombros e na coluna. Dizia ser "pelego"* até o momento em que se lesionou e, quando voltou ao trabalho, } \\
\text { se viu desamparado e passou a sofrer. }\end{array}$ \\
\hline Pedro & $\begin{array}{l}\text { Lesões nos ombros e acidente de trabalho. Após período de afastamento, voltou ao trabalho e foi diagnosticado com } \\
\text { depressão, apresentando sofrimento psíquico intenso relacionado ao trabalho. }\end{array}$ \\
\hline João & $\begin{array}{l}\text { Era quieto e observador. Dizia se sentir contemplado pelo relato dos demais participantes. Tinha lesões físicas e } \\
\text { dizia que era muito estressado e sem perspectivas de futuro. }\end{array}$ \\
\hline Matias & Lesões nos ombros e nos punhos. Afirmava ter planos para sair da empresa assim que tivesse condições. \\
\hline Samuel & $\begin{array}{l}\text { Lesões nos ombros, na coluna e nos punhos. Era quieto e observador e dizia se identificar com o relato dos demais } \\
\text { participantes. Sonhava com viver no interior para ter uma vida mais tranquila e sem tanto sofrimento. }\end{array}$ \\
\hline Mateus & $\begin{array}{l}\text { Lesões nos ombros, na coluna, nos punhos e nos joelhos. Dizia se sentir assediado, perseguido e humilhado. } \\
\text { Relatava trabalhar em uma função incompatível. Afirmava que o sofrimento no trabalho interferia em seus demais } \\
\text { relacionamentos. }\end{array}$ \\
\hline Estevão & $\begin{array}{l}\text { Lesões nos ombros, na coluna, nos punhos e nos joelhos. Apesar de relatar intenso sofrimento, dizia tentar viver de } \\
\text { forma otimista. }\end{array}$ \\
\hline
\end{tabular}

*Pelego é um termo utilizado pelos trabalhadores e, principalmente, pelo movimento sindical para designar aqueles que são aliados às empresas e aos patrões e, portanto, contrários aos interesses dos trabalhadores.

\section{Conhecendo a intervenção}

A proposta de intervenção foi elaborada e apresentada aos profissionais do Cerest, que autorizaram e permitiram que a pesquisa fosse realizada em suas dependências. Mesmo após a autorização, surgiu uma inquietação de alguns profissionais que questionaram se, ao dar elementos para produção de reflexões mais críticas aos trabalhadores, não se produziria ainda mais sofrimento. Esse questionamento foi muito interessante e permaneceu vivo ao longo de todas as intervenções realizadas. A resposta a essa questão foi que estimular os trabalhadores a sair de um estado de alienação - ainda que, em um primeiro momento, isso pudesse lhes trazer sofrimento - possivelmente faria com que se apropriassem melhor de suas realidades e contextos, retirando-lhes a culpa pelo adoecimento e mobilizando enfrentamento individual e coletivo. Recorrendo às discussões de Paulo Freire ${ }^{23}$, vemos que a presença consciente no mundo faz com que os indivíduos não escapem de suas responsabilidades éticas no seu mover-se no mundo. Assim,

$\mathrm{O}$ fato de me perceber no mundo, com o mundo e com os outros, me põe numa posição em face do mundo que não é a de quem nada tem a ver com ele. Afinal, minha presença no mundo não é de quem a ele se adapta, mas a de quem nele se insere. É a posição de quem luta para não ser apenas objeto, mas sujeito também da história. Gosto de ser gente porque, mesmo sabendo que as condições materiais, econômicas, sociais e políticas, culturais e ideológicas em que nos achamos geram quase sempre barreiras de difícil superação para o cumprimento de nossa tarefa histórica de mudar o mundo, sei também que os obstáculos não se eternizam. ${ }^{23}$

Reconhecendo a historicidade dos seres humanos, enquanto seres condicionados, mas não determinados, o futuro passa a ser entendido de forma problemática e não inexorável. Nesse sentido, os que adoeceram não são mais considerados culpados e podem ser impulsionados a tomar as rédeas de suas 
próprias vidas e histórias, de forma individual e coletiva. O enfrentamento coletivo, por exemplo, poderia gerar união e solidariedade entre os trabalhadores, favorecendo o confronto com a realidade tão dura, competitiva e individualista a que estamos todos submetidos. Foi nesse sentido que a intervenção ocorreu.

O primeiro encontro do grupo teve por objetivo apresentar a proposta de intervenção e saber se havia interesse dos trabalhadores em participar, bem como estabelecer um vínculo inicial, construir um cronograma e já levantar alguns temas que pudessem ser relevantes ao longo dos encontros grupais. Tentou-se deixar claro o caráter aberto do grupo, a fim de que os trabalhadores pudessem participar de forma ativa, dando forma à construção coletiva, para que ela fosse alinhada à demanda apresentada e aos seus interesses.

Compareceram cinco trabalhadores que, inicialmente, aparentavam estar ansiosos, mas foram se tranquilizando ao longo da conversa. Durante o encontro, eles se apresentaram, assim como a pesquisadora e uma profissional do Cerest que acompanhava a atividade. A maioria deles se mostrou comunicativa e disposta a participar. Desde a apresentação, compartilharam o quão penoso era o cotidiano de trabalho e os esforços físicos e mentais que despendiam para conseguir realizar suas atividades laborais.

Ao longo desse primeiro encontro, os trabalhadores presentes disseram que tinham interesse em participar do grupo de reflexão, pois sentiam necessidade de conversar sobre o trabalho e sua relação com a saúde mental. Em conjunto, foi combinado que o grupo se realizaria ao longo de seis meses, com frequência quinzenal e duas horas de duração por encontro, nas dependências do Cerest. Vinculou-se o dia do grupo a um dia da semana em que os trabalhadores necessariamente faziam tratamento médico para facilitar-lhes o comparecimento.

Para finalizar o primeiro encontro, estabeleceu-se também a questão do sigilo do grupo e da pesquisa, que manteria suas identidades preservadas. Todos os presentes assinaram o Termo de Consentimento Livre e Esclarecido (TCLE), que foi também assinado por outros participantes que compareceram nos demais encontros. A partir de então, iniciou-se formalmente a intervenção grupal, que durou os seis meses propostos. Ressalta-se que, no segundo encontro, compareceu o dobro de participantes, e a presença da maioria deles foi mantida durante os meses que se seguiram.

Com relação às estratégias empregadas durante os encontros, a mais utilizada foi promover rodas de conversa para discussão de temas e compartilhamento de experiências; mas também foram utilizadas algumas materialidades mediadoras - estratégia metodológica descrita por Souza, Petroni e Dugnani ${ }^{24}$ - como elementos disparadores de discussão. As materialidades mediadoras são elementos culturais e artísticos, sendo entendidas enquanto promotoras potenciais do desenvolvimento da consciência, já que fazem com que os sujeitos entrem em contato consigo e com o mundo, atribuindo sentidos e significados às suas vivências. Assim, houve a exibição de filmes, como Operárias do mundo ${ }^{25}$ e Tempos modernos ${ }^{26}$, além de fotos, charges $^{27}$ e trechos textuais. Essas materialidades eram apresentadas no início da reunião do grupo e, em seguida, se discutia seu conteúdo, buscando-se relações com as experiências cotidianas dos participantes no trabalho. Foram realizadas também atividades de desenho e escrita, utilizando-se materiais como folhas de papel sulfite, canetas coloridas, lápis grafite e lápis colorido, entre outros. Houve, ainda, um encontro em que se fez uma técnica de relaxamento, com música, para que os participantes se soltassem e sentissem seu corpo e suas emoções.

O Quadro 2 apresenta as materialidades mediadoras e os respectivos encontros em que foram utilizadas. Tentou-se escolher filmes, livros e figuras que abordassem o tema de modelos de organização do trabalho, de forma crítica e reflexiva, para promoção de discussão e debate. Após o contato com as materialidades, os trabalhadores discutiam suas impressões e a relação delas com seu trabalho e seu processo de saúde-adoecimento.

Quadro 2 Materialidades utilizadas ao longo dos encontros com o grupo de reflexão

\begin{tabular}{|l|l|c|c|c|}
\hline $\begin{array}{c}\text { Tipo de } \\
\text { material }\end{array}$ & \multicolumn{1}{|c|}{ Nome } & Ano & Autor & $\begin{array}{c}\text { Encontro em } \\
\text { que foi utilizado }\end{array}$ \\
\hline Filme & Operárias do mundo ${ }^{25}$ & 2000 & Diretor Marie Collard & 3 \\
\hline Texto & ${\text { A organização do trabalho no século } 20^{28}}^{28}$ & 2007 & Geraldo Augusto Pinto & 4 \\
\hline Texto & $\begin{array}{l}\text { Trabalho duro, discurso flexível: uma análise das contradições do } \\
\text { toyotismo a partir da vivência de trabalhadores }\end{array}$ & 2009 & Márcia Hespanhol Bernardo & 4 \\
\hline Charge & Frank e Ernest $^{27}$ & 1997 & Thaves (publicado no Jornal do Brasil) & 4 \\
\hline Filme & Tempos modernos $^{26}$ & 1936 & Diretor Charles Chaplin & 4 \\
\hline
\end{tabular}


Dos onze encontros realizados, os nove primeiros foram destinados à intervenção propriamente dita e, entre as temáticas discutidas, destacam-se o trabalho no capitalismo, a culpabilização dos trabalhadores pelo adoecimento, suas histórias e seus novos projetos de vida, estratégias individuais e coletivas para enfrentamento das condições e da organização precarizada de trabalho, e importância da união e da solidariedade entre os trabalhadores. Esses temas não foram pré-estabelecidos, mas definidos juntamente com os participantes no decorrer da intervenção.

Os dois últimos encontros tiveram a finalidade de discutir o processo de desenvolvimento da consciência coletiva do grupo e as possibilidades de ações que daí poderiam surgir. Além disso, foram realizados encaminhamentos específicos de atendimento à saúde de cada participante, pois, ao longo da intervenção, identificou-se que a maioria necessitava também de algum tipo de acompanhamento individual de saúde, seja física ou mental. Foram fornecidos, ainda, relatórios contendo uma síntese individual da participação durante o grupo. Assim, cada participante teve um relatório diferente, que continha o objetivo do grupo, em quantos encontros compareceu e quais os temas discutidos.

Após o término da pesquisa, houve dois momentos de feedback: o primeiro voltado à equipe técnica do Cerest, e o segundo, aos trabalhadores participantes. A devolutiva para os profissionais do Cerest consistiu em uma apresentação da pesquisa finalizada, contendo todas as suas etapas, seus resultados e análise. A apresentação foi realizada em um dia de reunião de equipe e contou com a participação da maioria dos profissionais, além da coordenadora municipal de saúde do trabalhador. Foi um momento que gerou debates sobre a importância da atenção à saúde mental do trabalhador, com atividades de assistência ou de prevenção, e também sobre a necessidade de um psicólogo dentro do serviço, que atualmente não conta com esse profissional em seu quadro de funcionários.

Já a devolutiva para os trabalhadores participantes consistiu na apresentação da pesquisa finalizada em um encontro no Cerest. Essa ocasião foi muito interessante, pois disseram que a pesquisa dava visibilidade a eles, que, muitas vezes, se sentiam tão invisíveis. As análises foram validadas pelos trabalhadores, que incentivaram ampla divulgação da pesquisa. Foi pedido que opinassem se sentiam-se resguardados o suficiente quanto às suas identidades e às vivências, e eles disseram que se sentiam contemplados e protegidos. Por se tratar de uma pesquisa fruto do processo de mestrado de uma das autoras, os trabalhadores foram convidados para a defesa da dissertação. Alguns compareceram nessa ocasião e, mais uma vez, disseram estar felizes por alguém dar visibilidade às suas vivências.

\section{Discutindo a intervenção}

O foco dado nos resultados e na discussão deste relato diz respeito à intervenção, e não às informações coletadas ao longo do processo grupal realizado. A experiência da pesquisadora com os trabalhadores participantes foi muito enriquecedora graças a um vínculo bastante produtivo estabelecido entre ambas as partes e também devido à grande riqueza das informações compartilhadas pelo grupo.

Quando os encontros envolveram materialidades mediadoras para disparar a discussão (filmes, textos e imagens), dinâmicas de grupo, desenhos e escrita, os trabalhadores mostraram-se surpresos e deslumbrados, evidenciando que essas estratégias eram pouco vivenciadas em seus cotidianos. Nesse sentido, foi possível ver, conforme apontam Souza, Petroni e Dugnani ${ }^{24}$, que a arte tem a capacidade de acessar a subjetividade e o sensível dos sujeitos. Os encontros 5 e 7, por exemplo, envolveram a criação de uma linha do tempo de suas vidas e, para isso, os trabalhadores tiveram à sua disposição diversos materiais, como revistas, canetas coloridas, lápis de cor, folhas de papel sulfite, entre outros. Nessas ocasiões, eles demonstraram interesse e empolgação. Foram momentos muito significativos, em que puderam deixar a criatividade e a imaginação fluírem.

De forma geral, os encontros grupais foram muito ricos. Foi possível conhecer histórias de muito sofrimento, de trabalhadores que encontraram na indústria automobilística uma chance de ascensão social. Porém, ao se entregarem de corpo e alma à empresa, "vestindo a camisa" (expressão utilizada pelo discurso gerencial do modelo toyotista, conforme afirma Bernardo ${ }^{21}$ ), a vivência do desgaste e do processo de saúde-adoecimento relacionado ao trabalho foi se intensificando. Em troca da fiel dedicação à empresa, os trabalhadores sofreram lesões por esforços repetitivos, foram submetidos a um controle exacerbado e a uma grande exigência de alto ritmo de produção, além de exposição a violência psicológica, assédio moral, entre outros aspectos que transformaram os seus sonhos em um grande pesadelo, conforme expressão deles ao longo do processo grupal.

Frente a isso e considerando o embasamento teórico já descrito na introdução deste artigo, a intervenção teve como foco o fornecimento de elementos que promovessem condições para uma reflexão mais crítica, estimulando os trabalhadores a enfrentar a realidade precarizada do trabalho, de forma individual e principalmente coletiva. O termo "reflexões mais críticas", ressaltado algumas vezes ao longo do texto, é pautado em Paulo Freire ${ }^{23}$ e em Martín-Baró ${ }^{9}$, que defendem o processo grupal enquanto espaço importante para promoção da união e da solidariedade entre seus membros. 
Muitos participantes do grupo de reflexão se mostraram, em um primeiro momento, extremamente submissos e oprimidos frente à lógica capitalista e à empresa em que trabalhavam, e um dos objetivos buscados no grupo, seguindo as ideias dos autores $\operatorname{citados}^{9,23}$, foi mostrar o quão ativo e responsável cada um de nós pode ser para a construção de uma sociedade mais justa e para o enfrentamento das situações de desigualdade e injustiça.

A intervenção grupal tentou promover discussões que propiciassem que os trabalhadores se conscientizassem de que eles não adoeceram por serem frágeis, fracos ou incapazes, mas por estarem inseridos em um sistema que os oprime, de modo que tenham que buscar se adaptar ao máximo à organização do trabalho e à forma como se produz para conseguirem sobreviver e garantir seus empregos. Assim, tentou-se mostrar que eles só vivenciam esse processo por estarem em uma relação desigual. Freire ${ }^{23}$ afirma que a ideologia capitalista nos faz aceitar, mansamente, que a globalização financeira é uma invenção por si mesma, algo natural, que não se pode evitar ou alterar. No entanto, essa ideologia esconde "que ela vem robustecendo a riqueza de uns poucos e verticalizando a pobreza e miséria de milhões"23 (p. 124).

Partindo dessa noção, Martín-Baró ${ }^{29}$ discute o lugar da psicologia nesse contexto. O autor afirma que não é possível fazer psicologia, de forma comprometida, sem se assumir uma responsabilidade histórica que tenta transformar as condições dos oprimidos para que eles estejam conscientes, recuperem a memória histórica de suas condições e possam transformá-las também. É interessante ressaltar que esse processo não parte de um conhecimento superior, detido pelo psicólogo, a ser imposto àqueles com quem o profissional entra em contato. Pelo contrário, não há conhecimento superior, mas uma tentativa de explicitar as condições em que as pessoas vivem, como problemas de injustiça estrutural, de guerras, de alienação nacional, de opressão. MartínBaró $^{29}$, ao longo de sua obra, defende que, diante disso, as pessoas possam agir no mundo de forma consciente e comprometida com a transformação social.

De acordo com as palavras de Martín-Baró ${ }^{9}$, o papel do psicólogo envolve qualidade profissional, tendo em vista seu conhecimento e sua capacidade de responder às demandas que surgem no contexto em que ele se insere; envolve colaborar para a disseminação de valores mais justos e igualitários, ao contrário dos valores individualistas e competitivos que a ideologia capitalista defende; e atuar, acima de tudo, em prol da libertação do indivíduo e da sociedade. Libertação, defendida também por Freire ${ }^{23}$, enquanto rompimento dos homens com a coisificação, passando estes a se assumirem enquanto homens históricos, ativos e responsáveis, de forma engajada com a transformação de si e da sociedade.

Frente a isso, ao longo das intervenções, foi discutido com os trabalhadores que somente rompendo com os valores individualistas e competitivos que a ideologia capitalista prega seria possível enfrentar a precarização social e do trabalho na atualidade, diminuindo o adoecimento e favorecendo a saúde. A união, nesse sentido, é essencial, seja por meio do sindicato da categoria ou de grupos e associações construídas pelos próprios trabalhadores. Isso foi visto nos participantes do grupo apresentado aqui. No decorrer da intervenção, os trabalhadores participantes começaram a colaborar mais uns com os outros, por exemplo, fornecendo informações relevantes aos colegas sobre possíveis manobras da empresa para evitar a vinculação de seus problemas de saúde ao trabalho ou fortalecendo a proposta de participar mais ativamente de uma associação regional de trabalhadores adoecidos pelo trabalho. Ficava, assim, evidente a união e a solidariedade entre eles, que levaram essa amizade para além das intervenções, conforme seus próprios relatos. Nas palavras de um dos participantes do grupo, registradas no diário de campo número 10: "Passar por um determinado problema sozinho é uma coisa, mas passar por esse mesmo problema junto aos colegas é diferente, pois a gente vai se fortalecendo e isso é muito importante".

Tendo em vista o contexto em que nos encontramos, de desmontes de direitos sob o nome de reformas - trabalhista e previdenciária -, os desgastes sofridos pelos trabalhadores somente aumentarão, já que estes perderão direitos, vivenciarão ainda mais a injustiça social, a fragmentação dos vínculos empregatícios, a terceirização desenfreada, entre outras consequências. Portanto, realizar intervenções em prol da saúde dos trabalhadores, de forma comprometida com a transformação da sociedade, buscando torná-la mais justa e igualitária, é um grande desafio e, nesse sentido, reforça-se a importância da disseminação do tipo de grupo apresentado aqui. Para finalizar, vale lembrar as palavras de Paulo Freire ${ }^{23}$ : "Mudar é difícil, mas é possível".

\section{Contribuições de autoria}

Silva MP realizou a intervenção e foi responsável pela elaboração do manuscrito. Bernardo MH orientou a intervenção-pesquisa, colaborou na escrita do manuscrito e na aprovação da versão final publicada. Ambas assumem responsabilidade pública por todo o seu conteúdo. 


\section{Referências}

1. Bernardo MH, Oliveira F, Souza HA, Sousa CC. Linhas paralelas: as distintas aproximações da psicologia em relação ao trabalho. Estudos de Psicologia. 2017; 34(1):15-24.

2. Coutinho MC, Bernardo MH, Sato L, organizadores. Psicologia social do trabalho. Petrópolis: Vozes; 2017.

3. Bernardo MH, Sousa CC, Pinzón JG, Souza HA. A práxis da psicologia social do trabalho: reflexões sobre possibilidades de intervenção. In: Coutinho MC, Furtado O, Raitz TR. Psicologia social e trabalho: perspectivas críticas. Florianópolis: Abrapso; 2015. p. 16-39.

4. Stecher A. El campo de investigación sobre transformaciones del trabajo, identidades y subjetividad en la modernidad contemporánea - apuntes desde Chile y América Latina. In: Stecher A, Godoy L. Transformaciones del trabajo, subjetividad e identidades - lecturas psicosociales desde Chile y América Latina. Providencia: RIL Editores; 2014. p. 19-76.

5. Ministério da Fazenda (BR). Adoecimento mental e trabalho: a concessão de benefícios por incapacidade relacionados a transtornos mentais e comportamentais entre 2012 e 2016 - $1^{\circ}$ Boletim quadrimestral sobre benefícios por incapacidade 2017 [Internet]. Brasília, DF; 2017 [cited 2018 Nov 17]. Available from: http://www.previdencia.gov.br/ wp-content/uploads/2017/04/1\%C2\%BA-boletimquadrimestral.pdf

6. Bernardo MH, Pereira MS. O trabalho no contexto brasileiro atual e os compromissos da psicologia social. In: Rasera EF, Pereira MS, Galindo D. Democracia participativa, Estado e laicidade: psicologia social e enfrentamentos em tempos de exceção. Porto Alegre: Abrapso; 2017. p. 139-54.

7. Esteves EG, Bernardo MH, Sato L. Fontes do pensamento e das práticas em psicologia social do trabalho. In: Coutinho MC, Bernardo MH, Sato L, organizadores. Psicologia social do trabalho. Petrópolis: Vozes; 2017. p. 49-80.

8. Freire P. Pedagogia do oprimido. $56^{\mathrm{a}}$ ed. Rio de Janeiro: Paz e Terra; 2014.

9. Martín-Baró I. Crítica e libertação na psicologia: estudos psicossociais. Petrópolis: Vozes; 2017.

10. Lima MEA. Saúde mental e LER: a dimensão psicológica das LER. Belo Horizonte: Mimeografado; 2000.

11. Keppler ILS, Yamamoto OH. Psicólogos nos Centros de Referência em Saúde do Trabalhador. Rev Psicol Organ Trab. 2016;16(1):48-60.

12. Oddone I, Marri G, Gloria S, Briante G, Chiatella M, Re A. Ambiente de trabalho: a luta dos trabalhadores pela saúde. São Paulo: Hucitec; 1986.
13. Laurell AC, Noriega M. Processo de produção e saúde: trabalho e desgaste operário. São Paulo: Cebes-Hucitec; 1989.

14. Clot Y. Trabalho e poder de agir. Belo Horizonte: Fabrefactum; 2010.

15. Dejours C. Da psicopatologia à psicodinâmica do trabalho. Rio de Janeiro: Editora da Fundação Oswaldo Cruz; 2004.

16. Daniellou F, coordenador. A ergonomia em busca de seus princípios: debates epistemológicos. São Paulo: Edgard Blucher; 2004.

17. Sato L, Lacaz FAC, Bernardo MH. Psicologia e saúde do trabalhador: práticas e investigações na saúde pública de São Paulo. Estud Psicol. 2006;11(3):281-8.

18. Sato L, Araújo MD, Udihara ML, Franco MAJ, Nicotera FN, Daldon MTB, et al. Atividade em grupo com portadores de LER e achados sobre a dimensão psicossocial. Rev Bras Saúde Ocup. 1993;21(79):49-62.

19. Weber F. A entrevista, a pesquisa e o íntimo, ou: por que censurar seu diário de campo? Horiz Antropol. 2009;15(32):157-70.

20. Bernardo MH. Trabalho duro, discurso flexível: uma análise das contradições do toyotismo a partir da vivência de trabalhadores. São Paulo: Expressão Popular; 2009.

21. Salerno VL, Silvestre MP, Sabino MO. Interfaces LER/saúde mental: a experiência de um Centro de Referência em Saúde do Trabalhador do estado de São Paulo. Rev Bras Saúde Ocup. 2011;36(123):128-38.

22. Seligmann-Silva E. Trabalho e desgaste mental: o direito de ser dono de si mesmo. São Paulo: Cortez; 2011.

23. Freire P. Pedagogia da autonomia: saberes necessários à prática educativa. $4^{\mathrm{a}} \mathrm{ed}$. Rio de Janeiro: Paz e Terra; 2014.

24. Souza VLT, Petroni AP, Dugnani LA. A arte como mediação nas pesquisas e intervenção em psicologia escolar. In: Guzzo RS, MarinhoAraújo CM, organizadores. Psicologia escolar: identificando e superando barreiras. Campinas: Alínea; 2011. p. 261-85.

25. Collard MF. Operárias do mundo [DVD]. Brussels: Latitudes Production; 2000.

26. Chaplin C. Tempos Modernos [DVD]. Beverly Hills: United Artists Corporation; 1936.

27. Thaves B. Frank e Ernest. Jornal do Brasil. 1997 Feb 19.

28. Pinto GA. A organização do trabalho no século 20. São Paulo: Expressão Popular; 2007.

29. Martín-Baró I. O papel do psicólogo. Estud Psicol. 1996;2(1):7-27. 